\title{
Os professores e a educação inclusiva: identificação dos fatores necessários à sua implementação
}

\author{
Marian Ávila de Lima e Dias* \\ Simone Conceição Rosa \\ Patrícia Ferreira Andrade \\ Universidade Federal de São Paulo, Programa de Pós-Graduação em Educação. São Paulo, SP, Brasil
}

\begin{abstract}
Resumo: A pesquisa objetivou identificar fatores considerados necessários para a implementação da educação inclusiva ligados aos professores e sua atuação. Realizou-se um levantamento bibliográfico de textos acadêmicos sobre o tema; posteriormente, foram entrevistadas três professoras com experiência em educação inclusiva. A pesquisa bibliográfica identificou 20 fatores, que foram separados em três categorias: I - fatores relativos ao professor, II - fatores intraescolares e III - fatores sociais. Para as entrevistadas, a centralidade da educação inclusiva recai sobre os fatores relativos ao professor, em especial às suas características de personalidade, tais como afetividade e persistência, sem nenhuma menção aos fatores sociais. Tais respostas indicam concepções de escola e de inclusão em que o desempenho individual do professor é visto como independente do clima social e das políticas de implementação da educação inclusiva.
\end{abstract}

Palavras-chave: educação inclusiva, formação de professores, inclusão escolar.

\section{Introdução}

Desde a década de 1990 o Brasil adere e legitima a educação inclusiva por meio da assinatura de declarações internacionais e da promulgação de leis e decretos. Porém, no que tange a sua implementação, este ainda é um campo repleto de desafios. Um deles refere-se ao fato de que os objetivos da educação numa sociedade voltada para o consumo e para a competitividade constantemente se impõem como obstáculos ao ingresso e à permanência do aluno significativamente diferente. Também devem ser consideradas as relações entre os diferentes tipos de alunos e a configuração de subgrupos isolados do conjunto da escola, bem como as questões relativas ao currículo, métodos de ensino e de avaliação daqueles em situação de inclusão como temas centrais do debate. Dentre tais desafios, destacamos a formação dos professores como campo de investigação e reflexão. Historicamente, a formação de professores direcionada para a educação especial, voltada apenas ao ensino dos alunos com deficiência, baseou-se na vertente médico pedagógica (Jannuzzi, 2004; Mendes, 2006). Nesta concepção, a ênfase recaiu sobre o aluno, suas potencialidades e incapacidades, seu diagnóstico e as possibilidades de "reabilitação". Consequentemente, o insucesso escolar decorria de questões individuais, perdendo assim as perspectivas relacionadas às condições da escola para proporcionar o aprendizado de todos (Ainscow, Porter

* Autora correspondente: mariandias.dias@gmail.com
\& Wang, 1997; Booth \& Ainscow, 2002; Mittler, 2003; Pacheco et al., 2007).

Com a proposta da educação inclusiva, amplia-se a população a ser incluída na escola, uma vez que, diferentemente da educação especial, esta modalidade de educação diz respeito a todos aqueles tradicionalmente dela excluídos. Assim, a educação inclusiva também se refere às crianças e adolescentes pobres, negros, indígenas, imigrantes, em conflito com a lei, dentre outros.

Neste novo cenário, surgem ensaios e relatos de pesquisas abordando a importância das concepções de professores sobre a educação inclusiva para que sua implementação ocorra. Os estudos que consideram relatos ou histórias de vida de professores cuja experiência é bem sucedida em relação à educação inclusiva revelam que estes educadores manifestam uma atitude positiva e aberta à mudança diante de seus alunos, além de priorizarem a interação e a cooperação nas suas práticas cotidianas em sala de aula (Sekkel, 2003; Sekkel, 2005; Dal-Forno \& Oliveira, 2005). O papel do professor para essa formação é fundamental, pois não se trata unicamente de transmitir conhecimentos, mas da forma que o faz e de sua relação com o saber. A forma de transmissão como a que estamos entendendo aqui não se refere somente a técnicas, por mais que essas sejam imprescindíveis, mas ao engajamento do professor, à sua cumplicidade com o aprendizado do aluno, isto é, refere-se a princípios políticos e éticos (Crochík et al., 2009).

Sejam os preconceitos, as emoções, as atitudes, a formação ou as concepções, quais seriam os elementos 
considerados necessários para a implementação da educação inclusiva, em especial aqueles relativos à atuação dos professores descritos em artigos e livros de educação? E quais seriam os elementos identificados pelos professores da área? A hipótese levantada é a de que embora haja uma significativa produção bibliográfica sobre o tema, as concepções dos professores envolvidos com esta proposta educacional teriam pouca correspondência com os aspectos levantados pela literatura. A importância de sistematizar as contribuições de ambos os campos - produção acadêmica e a posição dos professores - se dá no sentido de buscar identificar quais elementos podem vir a ser mais explorados em ambos para que a educação inclusiva seja bem sucedida.

\section{Método}

\section{Procedimentos}

Na primeira etapa da pesquisa, realizou-se um levantamento bibliográfico a fim de verificar quais foram os elementos mencionados como de maior relevância para a implementação da educação inclusiva. Foi dada especial atenção a ensaios e relatos de pesquisa voltados para o papel do professor. Utilizou-se a base de dados Scielo para a coleta de artigos e a Biblioteca Digital de Dissertações e Teses da Universidade de São Paulo. Em ambos a palavra-chave "educação inclusiva" associada às palavras "professor" ou "formação de professores" foram buscadas no título, resumo e/ou palavras-chave do texto. Após a leitura de todos os artigos levantados, verificou-se que os fatores descritos poderiam ser divididos em três grandes grupos: I - fatores individuais; II - fatores intraescolares e III - fatores sociais. Tal divisão também se baseou na categorização Booth e Ainscow (2002) para verificar o grau de inclusão de uma escola, em que os autores também dividem os aspectos relativos à inclusão variando desde os mais individuais até os mais grupais.

A segunda etapa da pesquisa ocorreu em três escolas de Ensino Fundamental de $1^{\mathrm{a}}$ a $4^{\mathrm{a}}$ série (uma municipal, uma estadual e outra privada) que consideram adotar a educação inclusiva. As participantes foram três professoras indicadas pela diretoria de cada uma das escolas. Foram realizadas entrevistas semiestruturadas com as professoras a fim de registrar as suas experiências, posicionamentos e opiniões sobre os fatores necessários à implementação da educação inclusiva. As entrevistas seguiram um roteiro a partir da "Escala de atitudes frente à educação inclusi$v a$ " elaborada e validada por Crochík, Ferrari, Hryniewicz, Barros e Nascimento (2006) contendo sete questões sobre a formação do professor e suas opiniões sobre o aluno, os métodos e ritmos de aprendizagem na educação inclusiva (roteiro de entrevistas no Anexo I). Após a transcrição das entrevistas, todas as professoras tiveram a oportunidade de rever o material e fazer as alterações que julgassem necessárias. As entrevistas foram analisadas a partir da comparação entre os elementos mencionados pelas professoras como necessários para a implementação e para a sua atuação na educação inclusiva e aqueles categorizados durante o levantamento bibliográfico. Todos os procedimentos com os participantes foram previamente submetidos à aprovação de um comitê de ética e a concordância dos colaboradores foi devidamente registrada através da assinatura de um termo de consentimento após a informação sobre a pesquisa.

Para fins de apresentação e análise dos dados, as professoras entrevistadas e as respectivas escolas serão doravante denominadas de "A", "B" e "C.

\section{Resultados}

A pesquisa bibliográfica apontou como elementos para a atuação dos professores na educação inclusiva fatores agrupados em três categorias:

I - Fatores individuais: 1- formação e educação continuada; 2 - atitude favorável; 3 - utilizar um referencial teórico voltado à educação inclusiva; 4 - reflexão sobre a prática; 5 - reconhecer em si as emoções que a diferença significativa provoca.

II - Fatores intraescolares: 6 - gestão democrática; 7 - comunicação e espaços de discussão e reflexão; 8 - ambiente com possibilidade de considerar a afetividade e partilhar experiências; 9 - construção de um ambiente que proporcione a educação inclusiva e participação de todos; 10 - concepções favoráveis da comunidade escolar sobre a educação inclusiva; 11 - modo como a educação inclusiva foi implementada na escola e sensibilização da comunidade escolar para a educação inclusiva; 12 - apoio à educação inclusiva; 13 - equipe gestora favorável à educação inclusiva; 14 - ênfase na aprendizagem e no ensino cooperativos; 15 - qualidade das relações no ambiente escolar, criação e valorização da socialização; 16 - valorização do educador.

III - Fatores sociais: 17 - adotar um modelo social de dificuldades educacionais e situação de inclusão; 18 - participação da comunidade; 19 - políticas públicas; 20 - modelo social e econômico vigente.

Embora a pesquisa bibliográfica tenha revelado esta terceira categoria, os fatores citados pelas professoras entrevistadas se referem quase que exclusivamente àqueles pertencentes às categorias I e II, sendo mais detidamente analisados a seguir. As categorias e fatores levantados, além de revelar as tendências dos pesquisadores da área, serviram também para nortear a análise dos fatores a serem mencionados pelas professoras. As categorias elencadas devem ser entendidas como interdependentes e intrinsecamente relacionadas, suficientemente abrangentes para integrar os tipos de respostas dadas pelas entrevistadas.

\section{Discussão dos resultados}

Com relação ao levantamento bibliográfico, o primeiro aspecto que chama a atenção é a quantidade de elementos elencados em cada uma delas. Percebe-se que os fatores intraescolares (Fator II) compreendem a maioria, o que pode evidenciar como os textos investigados 
consideram importante o papel que as relações entre os profissionais e a escola exercem sobre a implementação e a consequente atuação dos professores na educação inclusiva. Os fatores relativos ao professor (Fator I) se dividem entre questões psicológicas, como as atitudes e o preconceito, e a qualidade da formação escolar do educador; já os fatores mais amplos, relativos ao clima cultural favorável à inclusão das minorias na sociedade (Fator III), são citados em menor quantidade e por um número menor de autores, o que revela que mesmo o fato de que as políticas públicas voltadas à inclusão alteram substancialmente a prática escolar, o fazer cotidiano da escola permanece visto como pouco articulado com a sociedade segundo esses textos.

A seguir serão apresentados detalhadamente os fatores 1 a 16, com comentários ou trechos dos depoimentos das entrevistadas relativos a estes fatores. Alguns dos fatores serão analisados de forma agrupada por terem sido mencionados conjuntamente pelas entrevistadas e por considerarmos que a sua articulação com os demais fatores não os comprometeria conceitualmente. Os fatores 17 a 20, embora tenham sido elencados pela literatura especializada, quase não foram citados pelas professoras.

\section{I-Fatores relativos ao professor}

1 - Formação e educação continuada. Este fator foi encontrado nos artigos de Almeida (2004); Carvalho (2005); Dal-Forno e Oliveira (2005); Duek e Oliveira (2005); Leite e Aranha (2005); Pagotti e Teixeira (2005); Ramos (2005); e Sekkel (2003). Comparando o que descrevem tais artigos e o conteúdo das entrevistas com as professoras, vemos que: a professora A teve sua formação inicial no Magistério, formou-se em Letras e cursou Pedagogia; a professora $B$ teve sua formação inicial no Magistério e formou-se em Pedagogia e a professora $\mathrm{C}$ formou-se em Pedagogia. Entretanto, todas consideram que durante o período em que frequentaram a universidade, não tiveram uma boa formação para atuar em educação inclusiva. A professora A, que estava no quinto semestre do curso de Pedagogia, afirma que a discussão sobre educação inclusiva é feita apenas com base na legislação. Embora se queixem de suas formações, duas professoras (A e C) fizeram cursos complementares voltados à educação inclusiva.

A percepção por parte das professoras de que não tiveram boa formação para atuar em educação inclusiva pode ser analisada de duas maneiras. Sob a perspectiva da história recente da matriz curricular dos cursos de formação superior voltados à educação, sabemos que de fato a questão da educação inclusiva permanece sob o rótulo de "novidade", restringindo-se, na maior parte dos cursos, aos aspectos legais da questão e que a reflexão sobre educação inclusiva de fato ainda é incipiente nas universidades (Ferrari \& Sekkel, 2007). Porém, um segundo aspecto pode ser analisado a partir da queixa das professoras: a esperança de que algum curso ou formação seria capaz de dar respostas às angústias diante do medo de lidar com alunos diferentes do modelo ideal, como uma forma de defesa diante do desconhecido. Tal ideia também é frequentemente expressa no valor depositado na figura do especialista da área de saúde, considerado pelas professoras como alguém que sabe mais do que elas próprias sobre a educação de seus alunos em situação de inclusão.

2 - Atitude favorável. Fator registrado por Casco (2007), Crochík et al. (2009), Dal-Forno e Oliveira (2005) e por Sekkel (2003). Todas as professoras se declararam favoráveis à educação inclusiva e consideraram essa postura fundamental para sua implementação. A professora B ressalta que é favorável à educação inclusiva com responsabilidade de todas as partes envolvidas no processo. As professoras A e B acreditam que os alunos em situação de inclusão deveriam permanecer algum tempo na sala regular e outra parte do tempo de aula com o professor especialista. Todas as professoras concordam que alguns alunos com dificuldades acentuadas devem receber atendimento individualizado ou especializado.

Entende-se aí que teríamos diferentes graus de inclusão tais como descritos por Booth e Ainscow (2002), e que poderíamos considerar que as professoras A e B são parcialmente favoráveis à educação inclusiva, uma vez que optam por ações segregadas com alguns tipos de alunos.

3 - Utilizar um referencial teórico voltado à educação inclusiva, descrito por Ainscow et al. (1997), Pacheco et al. (2007) e Ramos (2005). A professora A menciona que utiliza a teoria de Vygotsky, embora afirme que no caso do aluno em situação de inclusão:

você sabe que ele vai até ali e aquele é o limite dele, você continua jogando estímulo, mas você não tem aquela cobrança de saber o porquê ele não foi além, não, você vai jogando e vai esperando, assim, é como se você jogasse a sementinha na terra e ficasse esperando ela brotar.

A professora $B$ sente dificuldade em não ter materiais e não conhecer metodologias específicas para o trabalho com alunos em situação de inclusão; já a professora $C$ comenta que tem facilidade em trabalhar com as diferenças por estar numa escola que adota o referencial construtivista.

Estas diferenças quanto à presença e o uso de teorias no cotidiano escolar relatada pelas professoras pode ser creditada em parte pela natureza da instituição em que atuam (pública ou privada), porém também é digno de nota que, se por um lado as professoras concordam com a importância em adotar um referencial teórico descrito pelos artigos e teses pesquisados, por outro lado elas mesmas pouco relatam ler ou estudar.

4 - Reflexão sobre a prática, citado por Ainscow et al. (1997), Dal-Forno e Oliveira (2005), Leite e Aranha (2005) e Sekkel (2003). As professoras A e C procuraram formações específicas em cursos de curta duração ou em cursos de extensão para compreender melhor a educação inclusiva ou as possibilidades de trabalho com os alunos em situação de inclusão. A professora B troca informações com uma colega que se especializou: 
Com o E. eu trabalho com as letras móveis, a professora V. me auxilia, mas a gente tem que estar buscando o tempo todo, sem esquecer que eu tenho uma classe de 32 alunos que as mães querem que estejam lendo esse ano.

\section{A professora $\mathrm{C}$ menciona:}

Eu acho que o que é bem bacana é o interesse do professor de correr atrás de informação, de ler bastante, de procurar cursos sobre o assunto, então eu acho que isso é fundamental, estar sempre se atualizando em relação a esse assunto.

Embora a formação continuada seja bem vinda, vemos que as professoras entrevistadas percebem a necessidade de um aprimoramento como uma questão pessoal, reveladora do seu empenho individual. A ideia de "correr atrás", mencionada pela professora $\mathrm{C}$, deixa clara essa noção. Tal concepção favorece o sentimento de isolamento do professor diante da educação inclusiva, além de não garantir necessariamente que está ocorrendo uma reflexão sobre a prática por meio dos estudos.

O esforço em "correr atrás" também auxilia a manter nos professores a concepção de que adequar-se à educação inclusiva é tarefa individual, desobrigando a instituição escolar como um todo de promover ações para melhor qualificar todos os seus membros. Há uma valorização desta atitude individual das professoras, creditada por elas a características como tenacidade e persistência decorrentes da sua personalidade. Além disso, ressalta-se que a reflexão sobre o fazer pedagógico não precisa estar necessariamente ligada a um curso ou atividade acadêmica formal, possibilidade que não pareceu ser considerada pelas entrevistadas.

5 - Conhecer as emoções que a diferença significativa provoca, descrito em Carvalho (2006), Crochík et al. (2006), Gomes e Barbosa (2006) e Sekkel (2003, 2005): as três professoras entrevistadas contam que sentem tranquilidade e que aceitam muito bem os alunos em situação de inclusão. Nenhuma mencionou medo, pena ou rejeição. A professora A relata sentir ansiedade com relação à forma de desenvolver o trabalho com os alunos e aos resultados que pode alcançar. A professora B sente-se incomodada com "as coisas erradas que acontecem com relação à educação inclusiva" e a professora C gosta muito do vínculo afetivo que desenvolve com os alunos. As professoras comentam que o preconceito sempre surge em alguns colegas, principalmente com relação à aceitação do aluno em situação de inclusão. Para a professora A:

[Algumas professoras] falavam: "Eu não consigo, até de olhar a cara dele babando perto de mim me dá nojo". Então eu acho que se a pessoa não tem o amor mesmo, acho que não adianta, acho que a importância do especialista é exatamente essa. O especialista, quem vai lá procurar esse curso, é quem está disposto a trabalhar com a criança especial, então quando você joga a criança numa sala de um professor que não é especialista ele vai sempre se apoiar nisso: "Não foi a profissão que eu escolhi, eu não pedi isso, estão me obrigando a fazer o que eu não quero fazer", então ele vai fazer mal feito, vai atrapalhar a vida dele e a vida dessa criança pra sempre.

Embora as professoras não relatem suas próprias dificuldades diante de alunos significativamente diferentes, a professora A traz em seu discurso a ideia de que é necessário um amor diante do aluno em situação de inclusão, amor este que apenas alguns professores e o especialista possuiriam, retornando à antiga ideia do "dom" para ensinar, agora atualizada para a questão dos alunos em situação de inclusão. Já a professora $\mathrm{C}$ acredita que o preconceito pode ser superado com a convivência diária, observando como os outros profissionais desenvolvem o seu trabalho, com formação e com informação sobre os alunos e sobre as formas de trabalho em sala de aula. É interessante notar como a tendência das entrevistadas foi a de identificar o preconceito como uma atitude pertencente apenas aos outros membros da escola, não reconhecendo que elas mesmas possam apresentar eventuais sentimentos de rejeição. Ressalta-se também a valorização da afetividade como fator importante para as entrevistadas para que a educação inclusiva ocorra.

\section{II - Fatores intraescolares:}

6 - A autoridade democrática, 7 - Comunicação com a presença de espaços de discussão e reflexão, 8 Ambiente com possibilidade de considerar a afetividade e partilhar experiências e 14 - Ênfase na aprendizagem e no ensino cooperativos (Ainscow et al., 1997; Carvalho, 2005; Dal-Forno \& Oliveira, 2005; Duek \& Oliveira, 2005; Mantoan, 2001; Mittler, 2003; Pacheco et al., 2007; Pletsch, 2009; Ramos, 2005; Stainback \& Stainback, 1999).

Sobre estes fatores, a professora A comenta que na escola existe participação dos professores no planejamento pedagógico, mas não há algo específico sobre a educação inclusiva:

Sim, nos reunimos pra montar o planejamento, mas a parte inclusiva é ignorada. Se você tem um deficiente visual, como já aconteceu comigo, e precisar de umas letras móveis, eu tive que providenciar isso. Eu mesma comprei as letras com meu dinheiro e montei, não existe nada que te favoreça.

A afirmação denota um sentimento de isolamento nas relações entre a professora e a escola, além da dificuldade no estabelecimento de relações democráticas entre a escola e os professores no que tange à educação inclusiva. Quanto à comunicação com a coordenação, a professora A relata: 
Ele era meu aluno e ele foi tirado daqui por insistência da coordenação na época. . . Então, como você passa uma, duas, três, quatro vezes pra coordenação, mas você não está pedindo pra tirarem da sala, você está comunicando que os fatos estão acontecendo, até pra se poupar de maiores responsabilidades sozinho, aí eles convenceram a mãe a tirar daqui.

Com este depoimento, evidenciam-se divergências entre professora e coordenação. Tais divergências parecem gerar um sentimento de solidão na professora e comprometer a comunicação entre as duas partes. Apesar disso, a mesma professora assegura que todos os docentes são muito unidos, compartilham dificuldades e experiências e ajudam uns aos outros. Segundo a professora A, a escola não possui espaços para discussão ou reflexão e "essas crianças são invisíveis, essas crianças só servem para [alguns profissionais da escola] se lamentarem". A professora A teve o apoio de uma psicóloga que visitava a instituição para ajudá-la com o trabalho na sala de aula e considerou essa oportunidade muito produtiva; neste sentido a professora B conta com a ajuda de uma colega, com quem troca informações e experiências, e para a professora $C$ é interessante ter um trabalho que sustente o professor no aspecto emocional, para que ele não "se envolva só na parte do carinho".

Nas escolas B e C as professoras afirmam que existe uma postura democrática em termos administrativos e pedagógicos. Embora comentem tal postura, as professoras não se aprofundam nas afirmações neste sentido. A professora B comenta que, na escola, a discussão é realizada mais frequentemente no espaço informal. Embora tenham duas horas de trabalho pedagógico por semana, afirma que esse tempo não é suficiente para todos os assuntos que precisam ser discutidos e que "se a gente tivesse mais tempo seria o ideal. O ideal é a gente trabalhar um periodo só, se dedicar mais, ganhar mais". A professora $\mathrm{C}$ comenta que a escola proporciona uma formação a cada ano em que todos participam e que "os professores têm encontros [semanais] com coordenadores para estudar, então a gente tem, dentro desse cronograma, várias vezes que a gente discute sobre a inclusão".

A queixa sobre as dificuldades de relação entre as diferentes instâncias da escola por parte das professoras ao se referirem aos fatores 6 e 7 demonstra que tanto os textos como as entrevistadas consideram importante tais dimensões para que a educação ocorra. Porém, as professoras parecem compreender tal possibilidade de diálogo como uma conversa íntima, seja com alguém especializado em emoções e externo à escola, como citam a professora $\mathrm{A} e$ $\mathrm{C}$, seja uma colega, como mencionado pela professora $\mathrm{B}, \mathrm{e}$ não como um espaço institucional, cujo momento de compartilhar seja considerado parte das suas atividades profissionais em grupo. Assim, embora a pesquisa bibliográfica tenha identificado este aspecto como importante e as professoras também o mencionem, para elas este elemento é compreendido como da esfera da informalidade, e não como parte integrante de sua prática profissional.

Quanto ao trabalho coletivo, embora as professoras não tenham feito menção específica a esta prática, observamos que as salas de aula das escolas A e B têm carteiras individuais, organizadas em fileiras, o que nos leva a pensar que o trabalho individual prevalece naquelas instituições. $\mathrm{Na}$ escola $\mathrm{C}$ as carteiras são individuais e ficam organizadas em duplas ou em trios. Porém, para além do fato de haver ou não atividades coletivas, as professoras pareceram não associar esta prática à educação inclusiva, talvez ainda pautando uma atuação nesta área tendo como referência modelos individuais de atendimento herdados da educação especial. Observa-se, portanto, com relação ao fator 14, um descompasso entre aquilo que os textos da área propõem e as concepções das professoras.

Quanto aos fatores intraescolares 9 - Construção de um ambiente que proporcione a educação inclusiva e a participação de todos, 10 - Concepções da comunidade escolar sobre a educação inclusiva, 11 - Forma como a educação inclusiva foi implementada na escola e sensibilização da comunidade escolar para a educação inclusiva, 12 - Apoio à educação inclusiva e 13 - gestores favoráveis à educação inclusiva (Ainscow et al., 1997; Booth \& Ainscow, 2002; Carvalho, 2005, 2006; Masini, 2004; Sant'ana, 2005; Silva, 2005; Sekkel, 2003, 2005; Silveira \& Neves, 2006; Stainback \& Stainback, 1999;), para a professora $\mathrm{A}$, as lideranças da escola não estão envolvidas nem comprometidas com o processo de educação inclusiva. As professoras $\mathrm{B}$ e $\mathrm{C}$, entretanto, descrevem as chefias como muito competentes e preocupadas com a inclusão de todos os alunos.

De acordo com as respostas das professoras, a escola A não teve preparo para a chegada do primeiro aluno em situação de inclusão, não havendo uma preocupação em sensibilizar os funcionários para a educação inclusiva. Também não há, na escola, qualquer formação, curso ou espaço para discussão sobre o assunto. A professora A afirma também contar com a colaboração das famílias dos alunos, mas reforça que não tem apoio das lideranças da instituição. Para ela, a instituição não proporciona um ambiente inclusivo e aponta como características deste ambiente a adaptação de móveis, do espaço e a aquisição de materiais para desenvolver o seu trabalho. "Não, nós já tivemos até professor que veio trabalhar aqui com cadeira de rodas e ele foi educadamente avisado de que não havia espaço, porque a escola tem muitas escadas, não tem sala ambiente, não tem lugar pra receber".

Na escola B, antes da proposta de educação inclusiva havia uma classe especial, e alguns dos alunos desta classe já eram transferidos para a classe regular; assim, a professora considera que a implementação da educação inclusiva é prática antiga na escola. Porém, afirma não haver tempo para a discussão sobre educação inclusiva durante a Hora de Trabalho Pedagógico Coletivo (HTPC) e nenhuma formação específica é concedida pela instituição. É preciso ressaltar que as escolas $\mathrm{A}$ e $\mathrm{B}$ pertencem à rede pública $\mathrm{e}$ 
que, de acordo com as professoras, a prefeitura do município de São Paulo concede uma formação específica, mas poucos professores têm interesse e os que dobram o turno não têm a possibilidade de participar, já a rede estadual não oferece qualquer formação. A professora B acredita que a escola tem uma boa recepção e proporciona um ambiente inclusivo a todos, entretanto afirma que faltam mudanças no espaço físico, um menor número de alunos em sala de aula, a presença de um especialista e a redução do tempo que os alunos passam em sala de aula.

$\mathrm{Na}$ escola $\mathrm{C}$ os alunos em situação de inclusão sempre foram aceitos nas classes regulares, essa foi uma escolha da direção. A professora comenta que existem espaços de discussão sobre educação inclusiva e que a escola organiza uma formação específica uma vez por ano em que todos participam. Para ela, a instituição proporciona um ambiente arquitetonicamente inclusivo para todos e considera receber apoio da escola, da comunidade e das famílias.

A forma como a implementação da educação inclusiva se deu na instituição escolar (fator 11), se por convicção de seus gestores ou por força de lei, tem relação direta com os demais fatores no sentido do convencimento de que a educação inclusiva é a melhor para todos os alunos ali envolvidos. O que observamos nas respostas das professoras, mesmo com diferenças quanto a concepções de inclusão, é que estes fatores são também valorizados por elas, em concordância com aquilo que é preconizado na literatura da área. A queixa da professora $\mathrm{A}$ e a satisfação da professora $\mathrm{C}$ apontam, na verdade, para uma mesma compreensão de que a adesão à educação inclusiva deve ser parte de uma cultura escolar implementada pela coordenação e encampada por todos na escola.

Quanto aos fatores 15 - Qualidade das relações no ambiente escolar e 16 - Valorização do educador (Ainscow et al., 1997; Booth \& Ainscow, 2002; Carvalho, 2006; Duek \& Oliveira, 2005; Oliveira-Menegotto, 2010; Sekkel, 2003), a professora A menciona frequentemente a falta de apoio da equipe técnica e da direção com relação ao seu trabalho. Tal aspecto tende a comprometer não só a comunicação entre profissionais e a percepção de valorização dos professores, mas também a qualidade das relações no ambiente escolar em termos éticos e no desenvolvimento da confiança e da colaboração mútua. Apesar disso, a professora reconhece a união e a relação de cumplicidade entre professores e disse que mantém uma boa relação com as famílias dos alunos em situação de inclusão. A professora $\mathrm{B}$ considera que as relações entre todos na escola são muito positivas, que todos se ajudam, trocam experiências e que as lideranças são muito comprometidas em tudo que diz respeito à educação inclusiva. Ela descreve as famílias dos alunos em situação de inclusão como "maravilhosas". A professora $\mathrm{C}$ considera as relações muito positivas na escola em que atua. Houve um período em que deixou a escola e foi trabalhar em outro lugar, mas depois de alguns anos, voltou e foi muito bem recebida. Sobre as relações com as famílias dos alunos, comenta: isso é uma coisa que os pais gostam muito. Dizem: Olha que bacana! Todos os anos meu filho tem um colega que tem uma necessidade especial. A escola vê o meu filho como um todo, se o meu filho precisar de alguma coisa, o meu filho também vai ter um atendimento especial.

As três professoras veem a relação com os alunos em situação de inclusão como relações afetivas, carinhosas, e que possibilitam muita aprendizagem. A professora $\mathrm{C}$ comenta o papel do vínculo no processo de ensino e aprendizagem:

Então você tem que se aproximar, você tem que conhecer aquela criança, você tem que ganhar essa criança, fazer um vínculo forte com essa criança, pra fazer com que ele acredite em você, que ele confie em você, que ele saiba, que ele veja em você um parceiro, né? Esse vínculo é importantissimo.

Sobre estes elementos, a professora A relata perceber um descaso da coordenação da instituição para com o seu trabalho: "não existe apoio, na verdade o apoio que existe é da própria mãe. Quando você pega uma aluno que não tem o apoio da família, vocêfica sozinha".

A professora $\mathrm{C}$ sente-se como parte do todo e reconhece a contribuição da escola na realização do seu trabalho "eu acho que é o envolvimento de toda a instituição, isso é bacana porque você não pode fazer um trabalho isolado dentro da escola".

São percepções bem distintas as relatadas pelas professoras $\mathrm{A}$ e $\mathrm{B}$ em comparação à professora $\mathrm{C}$, mas $\mathrm{o}$ sentimento de desvalorização relatado tem estreita relação com o fator anterior; ao se destacar a qualidade das relações estabelecidas entre as pessoas envolvidas com a educação inclusiva como um fator importante para a sua implementação, já é possível ter uma ideia da valorização ou não dos professores dentro deste processo.

\section{III - Fatores sociais:}

19 - As políticas públicas foram mencionadas por Ainscow et al. (1997), Booth e Ainscow (2002) e por Pacheco et al. (2007). Quanto às professoras, a única a mencionar questões relativas a algum fator fora dos muros escolares foi a professora B, que afirmou sentir falta de valorização dos professores por parte dos órgãos públicos:

A prefeitura oferece cursos no periodo contrário ao das aulas, mas eu dobro o periodo. Os professores não têm dispensa do ponto para participarem dos cursos e a maioria dobra os periodos e não têm tempo disponivel. O Estado não oferece os cursos e a maioria dos cursos que existem fora são pagos.

Não se trata de uma menção direta às políticas voltadas à educação inclusiva, mas sim da queixa da 
professora diante da precariedade da carreira do professor da rede pública em geral. Tal afirmação também está relacionada ao fator 16, a respeito da valorização do professor, o que nos faz inferir que as entrevistadas estabeleceram pouca ou nenhuma relação entre as condições necessárias para a implementação da educação inclusiva e as escolhas da sociedade, dentre as quais as políticas públicas.

\section{Síntese das análises}

A análise comparativa entre cada um dos fatores apresentados e as entrevistas evidenciou a presença de alguma correspondência entre os fatores levantados pela literatura e as opiniões das professoras. Se, por um lado, as professoras entrevistadas não parecem identificar nelas mesmas a existência de sentimentos negativos com relação aos alunos em situação de inclusão, por outro, identificam colegas professores que manifestam ter "nojo" ou outros sentimentos de repulsa. As entrevistadas se declararam, em alguma medida, favoráveis à educação inclusiva, mas consideram ter uma formação inicial insuficiente para essa atuação, e embora tenham procurado uma formação específica ou novas metodologias para desenvolver o seu trabalho em sala de aula, relatam ler e estudar pouco e sentem falta de mais qualificações nessa área. As dificuldades decorrentes da falta de formação especializada e de apoio técnico nas salas de aula também foram relatadas nas pesquisas de Sant'Ana (2005), Dal Forno e Oliveira (2005) e Silveira e Neves (2006). Porém, consideramos que a capacidade de estudo e aprimoramento da própria formação está diretamente relacionada ao acolhimento por parte da escola das reflexões dos professores sobre seu trabalho e sua formação, o que exige mudanças nas formas de organização das escolas, além de implicar em "tempo para que os professores possam encontrar-se e se ajudarem, em equipes e em partenariados, de modo que possam explorar e desenvolver aspectos da sua prática" (Ainscow et al., 1997, p. 26).

As professoras A e B relatam sentir a falta de apoio, de envolvimento e de responsabilidade das lideranças da própria escola (professora A) ou das autoridades públicas que administram as escolas (professora B); poucas possibilidades de partilhar experiências ou de considerar a afetividade das pessoas envolvidas no processo de educação inclusiva, pouco espaço para a discussão ou reflexão de assuntos relacionados ao tema e, em geral, sentem-se pouco valorizadas, desmotivadas e sozinhas. Tal situação também é mencionada nas pesquisas de Duek e Oliveira (2005) e Silva (2009). Embora a situação da professora $\mathrm{C}$ seja diferente, a presença do especialista fora da sala de aula com seu aluno mantém a questão da aprendizagem e da socialização como assunto vivido de modo segregado ao restante da classe, tornando a exclusão destes alunos apenas uma questão de situações mais explícitas ou mais veladas. Se, no Brasil, a educação inclusiva deve ser adotada em todas as escolas de todos os níveis, as relações institucionais aqui verificadas não estão organizadas em torno de um ambiente que proporcione a participação de todos (educadores, alunos, familiares, funcionários e comunidade), fator que passa necessariamente por vias efetivas de comunicação, pela gestão democrática, pela boa qualidade das relações no ambiente escolar (em termos éticos, de confiança, de apoio e de colaboração) e pela adesão de todos à proposta de educação inclusiva.

O acesso e a aquisição de conhecimentos são uma das principais atribuições da escola. Uma educação inclusiva de qualidade demanda uma forte ênfase na aprendizagem cooperativa, no ensino colaborativo, na interação e no trabalho de grupo, tanto nas atividades diárias quanto no espaço físico, entre alunos, entre professores e entre estes e a equipe gestora da instituição. É fundamental que as escolas e os professores se atenham a este fator, que pelo que demonstram as entrevistas, necessita ser mais explorado, pois quando questionadas diretamente sobre quais seriam os fatores determinantes da sua atuação as professoras relataram: o apoio e a participação das famílias, a responsabilidade do Estado em preparar os professores e as escolas para a educação inclusiva e o envolvimento de toda a escola. Esses são também fatores considerados por outros autores (Carvalho, 2005; Leite \& Aranha, 2005, Gomes \& Barbosa, 2006) como importantes para a educação inclusiva ser bem sucedida. Contudo, o fator mais mencionado nas três entrevistas foi a atitude favorável por parte do professor. Este fator aparece fortemente em expressões como "disponibilidade pra trabalhar com alunos com necessidade especial", "estar disposto a incluir" os alunos, "estar a fim", "ter perfil", "ter amor", "persistir" e acreditar no trabalho. Certamente, a atitude favorável à educação inclusiva, por parte do professor, é extremamente importante no processo, mas essa atitude não deve ser encarada como um ato assistencialista decorrente de características de personalidade. Consideramos que todos os professores devem desenvolver plenamente suas habilidades para ensinar todos os alunos, quer estejam em situação de inclusão ou não. Ampliando a questão da formação, tais elementos são mencionados por Adorno (2000) como essenciais para a formação do homem: o amor como Eros, força agregadora, deveria estar contemplado na educação a fim de que todos, não apenas professores, tivessem a possibilidade de refletir sobre si, expressando sua singularidade. Sob tal perspectiva, é extremamente relevante que os professores tenham comprometimento e uma atitude favorável à educação inclusiva, mas isso não significa que devam enfrentar sozinhos as dificuldades que possam advir deste processo.

Com relação aos fatores categorizados como sociais, chama a atenção a quase ausência dessa dimensão na fala das entrevistadas. Consideramos que tal lacuna está associada à ênfase dada pelas professoras aos aspectos individuais, configurando-se como uma forma de expressão da relação dos indivíduos com a vida social em que os dois aspectos (indivíduo e sociedade) são percebidos como isolados.

\section{Considerações finais}

Obviamente não é possível esgotar nos elementos apresentados tudo aquilo que pode contribuir para o 
sucesso da educação inclusiva, e cada professor, bem como cada escola, possui diferentes prioridades de ações nessa direção (Booth \& Ainscow, 2002). A presença e a reflexão sobre os elementos mencionados tanto nos artigos como pelas professoras pode auxiliar na remoção gradativa das barreiras à participação de todos nas escolas, o que é condição essencial para implementar a educação inclusiva. Porém, a comparação entre as entrevistas e os dados mencionados pelas pesquisas indicam a necessidade de maior ênfase na formação dos professores nos aspectos políticos e éticos capazes de dimensionar a educação inclusiva como proposta coletiva capaz de contribuir significativamente na qualidade da educação.

Os fatores considerados mais importantes na percepção das professoras concentraram-se em apenas um dos três descritos pelas produções acadêmicas. Tais respostas indicam concepções de escola e de inclusão em que o desempenho individual do professor é visto como independente do clima social e das políticas de implementação da educação inclusiva, o que aponta para a necessidade de redirecionamento nas políticas de implementação da educação inclusiva a fim de que esta não seja tomada pelos professores apenas como um tipo de educação dependente de características pessoais de personalidade.

Embora os textos pesquisados elenquem diversos fatores, tal compreensão não é percebida no cotidiano das professoras entrevistadas. Há quase que uma ruptura entre o seu cotidiano escolar e os aspectos sociais relativos à escola, uma vez que suas menções àquilo que deveria ser levado em conta para a efetivação da educação inclusiva pouco ou nada se relacionam com a adoção de princípios sociais (tais como a igualdade e a tolerância), com a participação da comunidade mais ampla e com o modelo econômico vigente. Consideramos que os princípios éticos e políticos envolvidos na atitude favorável do professor quando do processo de inclusão de alunos mencionados no início deste artigo são parte central da formação dos professores, mas não podem ser confundidos com características individuais, como "paciência" ou "calma", uma vez que tais princípios estão intimamente ligados às decisões políticas envolvidas não apenas nos programas de formação de professores, mas, sobretudo, naquelas mais amplas, ligadas aos objetivos da educação e ao papel social da escola.

\section{Teachers and inclusive education: identifying factors required for its implementation}

Abstract: The present research aimed to identify the elements related to teachers and their performance in the inclusive education. A bibliographical survey of the elements presented in literature on inclusive education and a field research with three elementary school teachers was performed. There were identified 20 elements described in articles and books, which were divided in three categories: I - factors related to the teacher, II - factors internally related to the school and III - social related factors. For the interviewed teachers the unanimous factor that determines their performance is related to personality factors, such as kindness and persistence, without any mention to the social factors. Such results indicate views of school and inclusion in which the individual performance of teachers is seen as independent of social mood and the implementation of inclusive education policies.

Keywords: inclusive education, teacher training, school inclusion.

\section{Les maîtres et l'éducation inclusive: I'identification des facteurs nécessaires à sa exécution}

Résumé: La recherche visait à identifier les facteurs nécessaires à la mise en œuvre de l'éducation inclusive, en particulier ceux liés à la performance des enseignants. Une recherche documentaire a été effectuée, et ensuite ont été interrogées trois enseignantes ayant de l'expérience dans l'éducation inclusive. La recherche documentaire a identifié 20 facteurs répartis en trois catégories: I - les facteurs liés a la formation des enseignants, II - les facteurs intrascolaires et III - les facteurs sociaux. Pour les enseignantes interrogées, le facteur concerne les caractéristiques de la personnalité de l'enseignant, comment l'affection envers les enfants et la persistance, sans mention aux facteurs sociaux. Les réponses indiquent des concepts d'école et de l'éducation inclusive selon lesquels la performance individuelle d'enseignant n'a pas liaison avec les politiques publiques et les demandes sociales.

Mots-clés: education inclusif, formation des enseignants, inclusion dans l'école.

\section{Los profesores y la educación inclusiva: identificación de los factores necesarios para su implementación}

Resumen: La investigación tuvo como objetivo identificar los factores considerados necesarios para la implementación de la educación inclusiva relacionados a los profesores y su actuación. Se realizó una investigación bibliográfica sobre el tema; después tres profesoras con experiencia en educación inclusiva fueron entrevistadas. La búsqueda en la literatura identificó 
20 factores, divididos en tres categorías: I - factores relativos al profesor, II - factores intraescolares y III - factores sociales. Para las entrevistadas, lo principal en la educación inclusiva son los factores relativos al profesor, en especial sus características de personalidad, tales como afectividad y persistencia, sin ninguna mención a los factores sociales. Las respuestas indican concepciones de escuela y de inclusión donde el desempeño individual del profesor es visto como independiente del clima social y de las políticas de implementación de la educación inclusiva.

Palabras clave: educación inclusiva, formación de profesores, inclusión escolar.

\section{Referências}

Adorno, T. W. (2000). Educação e emancipação (2a ed.). São Paulo, SP: Paz e Terra.

Ainscow, M., Porter, G., \& Wang, M. (1997). Caminhos para as escolas inclusivas. Lisboa, Portugal: Instituto de Inovação Educacional.

Almeida, M. A. (2004). Formação do professor para a Educação Especial: história, legislação e competências. Revista de Educação Especial, 24, 23-32.

Booth, T., \& Ainscow, M. (2002). Index para a inclusão. Reino Unido: CSIE. (Versão produzida e traduzida pelo LAPEADE - Laboratório de Pesquisa, Estudos e Apoio à Participação e à Diversidade em Educação, Universidade Federal do Rio de Janeiro)

Carvalho, R. E. (2005). Educação inclusiva: do que estamos falando? Revista Educação Especial, 26, 19-30.

Carvalho, R. E. (2006). Educação inclusiva: com os pingos nos "is" (4a ed.) Porto Alegre, RS: Mediação.

Casco, R. (2007). Autoridade e formação: relações sociais na sala de aula e no recreio (Tese de Doutorado). Pontifícia Universidade Católica de São Paulo, São Paulo.

Crochík, J. L., Ferrari, M. A. L. D., Hryniewicz, R. R., Barros, O. N., \& Nascimento, R. B. (2006). Preconceito e atitudes em relação à Educação Inclusiva. Psicologia Argumento, 24(46), 55-70.

Crochik, J. L., Freller, C. K., Dias, M. A. L., Fefferman, M., Nascimento, R. B., \& Casco, R. (2009). Atitudes de professores em relação à educação inclusiva. Psicologia, Ciência e Profissão, 29(1), 40-59.

Dal-Forno, J., \& Oliveira, V. (2005). Ultrapassando barreiras: professoras diante da inclusão. Revista Educação Especial, 26, 99-106.

Duek, V. P., \& Oliveira, V. F. (2005). Inclusão de alunos com necessidades educacionais especiais no ensino regular: ressignificando a formação pessoal e profissional da educadora infantil. Revista Educação Especial, 25, 49-58.

Ferrari, M. A. L. D., \& Sekkel, M. C. (2007). Alunos com deficiência no ensino superior: um novo desafio. Psicologia, Ciência e Profissão, 27 (4), 636-647.

Gomes, C., \& Barbosa, A. J. G. (2006). Inclusão escolar do portador de paralisia cerebral: atitudes de professores do ensino fundamental. Revista Brasileira Educação Especial, 12(1), 85-100.

Jannuzzi, G. M. (2004). Educação do deficiente no Brasil. São Paulo, SP: Autores Associados.

Leite, L. P., \& Aranha, M. S. F. (2005). Intervenção reflexiva: instrumento de formação continuada do educador especial. Psicologia: Teoria e Pesquisa, 21(2), 207-215.

Mantoan, M. T. E. (Org.). (2001). Caminhos pedagógicos da inclusão: como estamos implementando a educação (de qualidade) para todos nas escolas brasileiras. São Paulo, SP: Memnon.

Masini, E. A. F. S. (2004). Uma experiência de inclusão providências, viabilização e resultados. Revista Educar, 23, 29-43.

Mendes, E. G. (2006). A radicalização do debate sobre inclusão escolar no Brasil. Revista Brasileira de Educação, 11(33), 387-405.

Mittler, P. (2003). Educação inclusiva: contextos sociais. Porto Alegre, RS: Artmed.

Oliveira-Menegotto, L. M., MartinI, F. O., \& Lipp, L. K. (2010). Inclusão de alunos com síndrome de Down: discursos dos professores. Fractal Revista de Psicologia, 22(1), 155-168.

Pacheco, J., Eggertsdóttir, R., \& Marinósson, G. L. (2007). Caminhos para a inclusão. Porto Alegre, SP: Artmed.

Pagotti, A. W., \& Teixeira, A. C. (2005). Inclusão escolar: o que dizem as professoras que trabalham em salas inclusivas? Comunicações - Revista do Programa de Pós-Graduação em Educação da Unimep, 1(1), 28-42.

Pletsch, M. D. (2009). Formação de professores para a educação inclusiva: legislação, diretrizes políticas e resultados de pesquisas. Revista Educar, 33, 143-156.

Ramos, D. K. (2005). Integrando as diferenças: crianças com necessidades especiais no ensino regular. Revista de Educação Especial, 26, 141-150.

Sant'ana, I. M. (2005). Educação inclusiva: concepções de professores e diretores. Psicologia em Estudo, 10(2), 227-234.

Sekkel, M. C. (2003). A construção de um ambiente inclusivo na educação infantil: relato e reflexão sobre uma experiência (Tese de Doutorado). Instituto de Psicologia da Universidade de São Paulo, São Paulo.

Sekkel, M. C. (2005). Reflexões sobre possibilidades e limites da educação inclusiva. Boletim de Psicologia, 55(122), 43-58.

Silva, M. O. E. (2009). Da exclusão à inclusão: concepções e práticas. Revista Lusófona de Educação, (13). Disponível em http://www.scielo.gpeari.mctes. $\mathrm{pt} / \mathrm{scielo}$.php? script $=\mathrm{sci}$ _arttext\&pid $=\mathrm{S} 1645$ $72502009000100009 \& \operatorname{lng}=\mathrm{pt} \& \mathrm{nrm}=\mathrm{iso}$

Silva, S. C., \& Aranha, M. S. F. (2005). Interação entre professora e alunos em salas de aula com proposta 
pedagógica de educação inclusiva. Revista Brasileira de Educação Especial, 11(3), 373-394.

Silveira, F. F., \& Neves, M. B. J. (2006). Inclusão escolar de crianças com deficiência múltipla: concepção de pais e professores. Psicologia: Teoria e Pesquisa, 22(1), 79-88.

Stainback, S., \& Stainback, W. (1999). Inclusão: um guia para educadores. Porto Alegre, RS: Artmed.

Recebido: 06/03/2014

Revisado: 28/10/2014

Aceito: $30 / 03 / 2015$ 


\begin{abstract}
ANEXOS
ANEXO I

Roteiro de entrevistas para os professores (baseado na Escala de atitudes frente à educação inclusiva, elaborado por Crochík et al., 2006)

1 - Qual a sua posição em relação à educação inclusiva?

2 - Como você trabalha com os seus atuais alunos em situação de inclusão? (métodos e ritmos de aprendizagem diferentes dos demais?)

3 - Quais expectativas você tem em relação a esses alunos? (socialização, aprendizagem...)

4 - O que seria necessário na sua escola para que se tornasse mais inclusiva?

5 - Como é o apoio da coordenação e da direção para o trabalho com os alunos em situação de inclusão?

6 - Há interação entre os professores para o planejamento das ações pedagógicas relativas aos alunos em situação de inclusão? Como isso ocorre?

7 - Percebe os alunos de inclusão como incluídos? De que forma? O que mais poderia ser feito para melhorar isso?
\end{abstract}

